\title{
A cross-sectional assessment of symptom burden among patients with advanced cervical cancer
}

\author{
Tolcha Kebebew ${ }^{1 *}$, Azwihangwisi Helen Mavhandu-Mudzusi² ${ }^{2}$ and Annah Mosalo ${ }^{2}$
}

\begin{abstract}
Background: The increasing burden of chronic non-communicable diseases in developing countries is driving attention to palliative care services. Identification of disease-specific symptoms of concern and their prevalence will guide designing, monitoring, and evaluating palliative care programmes. This study assessed the burden of symptoms and problems among patients with advanced cervical cancer.

Methods: This research followed a cross-sectional study design to quantitatively review the symptom burden among patients diagnosed with advanced cervical cancer attending treatment at Tikur Anbessa Specialised Hospital, Addis Ababa, Ethiopia from January to July 2019. Symptoms were assessed using a patient-reported, seven-day recall Integrated Palliative Care Outcome Scale (IPOS) version III. Frequency, median and mean scores with a standard deviation were used in the descriptive analysis whereas t-test and one-way analysis of variance were used for comparisons.

Results: There were 385 patients with advanced cervical cancer, stage IIB-IVB, successfully interviewed. The median age was 50 years, the majority were illiterate (63.1\%) and in marital union (62.3\%). Over 50\% of the patients experienced pain, weakness, poor appetite, constipation, limited mobility, and dry mouth. The burdens of emotional symptoms such as patient anxiety, family anxiety, and patient depression were also prevalent at $79.7 \%, 82.3 \%$, and $47.0 \%$, respectively. Patients who are illiterate, at a higher stage of the disease, not currently in marriage, and who received palliative radiotherapy bear a higher symptom burden.
\end{abstract}

Conclusion: Patients with advanced cervical cancer bear a high symptom burden. Early initiation of palliative care is recommended to alleviate the concerning symptoms, and to improve patients' quality of life.

Keywords: Advanced cervical cancer, Cross-sectional assessment, Symptom burden, IPOS, Palliative care, Ethiopia

\section{Background}

The burden of chronic and non-communicable diseases increases as countries go through an epidemiologic transition [1]. There is insufficient documentation of the prevalence of non-communicable diseases in Ethiopia; however, studies such as Global Observatory of Cancer (GLOBACAN) estimate a high prevalence of cancer

\footnotetext{
*Correspondence: tolchakebebew@gmail.com; 58553312@mylife.unisa.ac.za 1 Student at University of South Africa, Ethiopia Learning Centre, Addis Ababa, Ethiopia

Full list of author information is available at the end of the article
}

[2-4]. The incidence and mortality rate of cervical cancer was the highest in Sub-Saharan African countries with an estimated 34.8 cases and 22.5 deaths per 100,000 population in 2012 [3]. In the Eastern African region, the number is higher, with an incidence rate of 40.1 and a death rate of 30.0 per 100,000 population in 2018 [4]. Breast cancer and cervical cancer are the leading causes of mortality and morbidity among women in Ethiopia [5]. Coupled with an increased proportion of aged people, as the life expectancy has grown from 48 years in 1990 to 
66 years in 2015 in Ethiopia [6], chronic diseases pose a greater demand for palliative care services $[7,8]$.

Palliative care is comprehensive care provided to patients with life-threatening disease conditions to improve the quality of life of the patients and their families [9]. It includes pain control, symptom management, and emotional, socio-economic, psychological and spiritual support, whilst providing the patients with dignity and peace at the end-of-life [9]. In most chronic and life-threatening diseases, the prognosis of cervical cancer after advanced treatment might be poor. Therefore, early initiation of palliative care will help patients and their families as well as the health care workers to avoid ineffective but costly treatments [10].

Assessment and evaluation of palliative care needs can be measured at different levels throughout the care process including the structure, the process, and outcome [11]. However, the most important indicator of palliative care is the outcome status, measured through symptoms and quality-of-life attributes. In the past, having a standardised tool to measure palliative care needs and outcome of the care and support interventions have been a challenge. However, recently there have been different measurement scales developed [11-14]. The Integrated Palliative Care Outcome Scale (IPOS) is one of the most common tools designed to measure the palliative care status [12].

Studies on cervical cancer-specific patient outcomes are lacking in Ethiopia. The outcome measures and the symptom burden estimates could help to design targeted palliative care interventions and to guide the monitoring and evaluation of disease-specific palliative care and support programmes. This study evaluated the burden of symptoms and problems, using the IPOS, and identified the most common symptoms among patients with advanced cervical cancer attending radiotherapy in Addis Ababa, Ethiopia.

\section{Methods}

This study utilised a cross-sectional design using a quantitative approach to assess the burden of the symptoms and problems. Findings of this study were compiled and reported following the "Strengthening the Reporting of Observational Studies in Epidemiology (STROBE)" guidelines [15].

Interviews were conducted with patients diagnosed with advanced cervical cancer, stages IIB-IVB, attending treatment at the Radiotherapy Centre of the Tikur Anbessa Specialised Hospital in Addis Ababa, Ethiopia, from January to June 2019. The hospital is the only oncology centre in the country that provides comprehensive and specialised cancer treatment and care to patients referred from health facilities across the country.

The sample size was determined using the calculation formula for single population proportion studies. Using a proportion of $50 \%$, a $95 \%$ confidence level and level of precision of $5 \%$, the sample size (n) was 385 using the formulae: $\left[Z_{\alpha / 2} / E\right]^{2} p q$, where $Z_{\alpha / 2}$ is 1.96 , proportion (p) and $q(1-p)$ were 0.5 each, and the level of precision (E) was 0.05 . Considering an additional $5 \%$ for nonresponse rate, the final sample size was 404 .

Participants included in this study were selected by the following criteria: histologically confirmed diagnosis of cervical cancer, stage IIB-IVB according to the International Federation for Gynaecology and Obstetrics (FIGO) [16], age above 18 years, those who were conscious, stable and able to communicate during the interview, and patients who gave consent to participate in the study. After identifying the stage of the disease from patient cards, through the help of hospital nurses, eligible patients were identified each day and included in the study. Whenever there were more than three eligible patients per data collector for each day, we used the simple random sampling technique to select the participants.

The principal researcher, assisted by trained hospital nurses, collected the data using a structured and pretested questionnaire that included the seven-day recall IPOS version III to assess the symptom burden. The IPOS scale is composed of items used to measure pain and other symptoms. It is a recommended item used to measure the physical, psychological and mental status and needs among people affected by severe and chronic diseases, including cancer $[17,18]$. The IPOS has been adapted and tested in different countries and languages [18-22]; and for different types of diseases including cancer [22], heart failure [23, 24], renal diseases [21], and dementia [25].

Data entry and cleaning were done using CS Pro 7.1 software. The data were then transferred to Stata $12^{\circledR}$ for analysis. A description of all dependent and independent variables was conducted using frequency, percentage, mean, median, range, or standard deviation, and presented in tables and graphs. The aggregate IPOS scores were compared among different variables using $\mathrm{t}$-test and one-way analysis of variance.

The Research Ethics Committee in the Department of Health Studies, University of South Africa (UNISA), and the Institutional Review Board of the College of Health Sciences, Addis Ababa University granted approval for this study. The Radiotherapy Center of Tikur Anbessa Specialised Hospital also reviewed and approved the study protocol. Each study participant received information on the objectives of the study and the data collection 
Table 1 Socio-demographic and treatment information of patients with advanced cervical cancer, TASH, Ethiopia, 2019 $(n=385)$

\begin{tabular}{|c|c|c|}
\hline Patient characteristics & Number & Percentage \\
\hline \multicolumn{3}{|l|}{ Age (Years) } \\
\hline Below 50 & 147 & 38.2 \\
\hline 50 and above & 238 & 61.8 \\
\hline \multicolumn{3}{|l|}{ Educational status } \\
\hline Illiterate & 243 & 63.1 \\
\hline Literate & 142 & 36.9 \\
\hline \multicolumn{3}{|l|}{ Marital status } \\
\hline Currently in marriage & 240 & 62.3 \\
\hline Currently not in marriage $^{a}$ & 145 & 37.7 \\
\hline \multicolumn{3}{|l|}{ Occupation } \\
\hline No job & 123 & 32.0 \\
\hline Housewife & 81 & 21.0 \\
\hline Farming & 72 & 18.7 \\
\hline Others $^{b}$ & 109 & 28.3 \\
\hline \multicolumn{3}{|c|}{ Average monthly income (in USD) } \\
\hline Below 50.00 & 324 & 84.2 \\
\hline 50.00 or more & 61 & 15.8 \\
\hline \multicolumn{3}{|l|}{ Cancer stage } \\
\hline$\| \mathrm{B}$ & 90 & 23.4 \\
\hline III (A or B) & 105 & 27.3 \\
\hline IVA & 162 & 42.1 \\
\hline IVB & 28 & 7.3 \\
\hline \multicolumn{3}{|l|}{ Treatment modality ${ }^{c}$} \\
\hline Surgery & 39 & 10.1 \\
\hline Chemotherapy & 135 & 35.1 \\
\hline Therapeutic radiotherapy & 139 & 36.1 \\
\hline Palliative radiotherapy & 216 & 56.1 \\
\hline
\end{tabular}

TASH Tikur Anbessa Specialized Hospital, USD United States Dollar

${ }^{\mathrm{a}}$ includes single or dissolved marriage; ${ }^{\mathrm{b}}$ Others include retired, employees, petty traders and daily labourers; ${ }^{C}$ multiple responses possible

procedures and gave informed consent before the interview. The participants were also provided with participant information sheet. Names and personal identifiers were kept separate from the actual data and reports to maintain confidentiality.

\section{Results}

\section{Patient characteristics}

A total of 385 patients with advanced cervical cancer were successfully interviewed. The age ranged from 20 to 80 years, with a median of 50 years (Table 1). About $98 \%$ $(n=376)$ were patients aged 35 years or more. Nearly one-third $(n=138)$ were among the age group of 35 to 49 years, another one-third $(n=125)$ among the age group of 50 to 60 years, and the rest were more than 60 years of age.
Most of the study participants (243, 63.1\%) were illiterate, while 119 (30.9\%) attended up to secondary education. In total, $240(62 \%)$ were married while $97(25.2 \%)$ and 40 (10.4\%) were widowed and divorced, respectively. One hundred and eleven (28.8\%) study participants were unemployed at the time of the study, $84(21.8 \%)$ were housewives, $72(18.7 \%)$ were farmers, and $44(11.4 \%)$ were petty traders; government or private employees constituted less than $10 \%(n=34)$. The median monthly income was 812.00 Birr (equivalent to 27.07 USD), while only 35 (9.1\%) of the participants had a monthly income of 3000.00 Birr (100.00 USD) or higher.

All the study participants had a confirmed diagnosis of advanced cervical cancer, FIGO stage IIB-IVB. Most of the participants $(162,42.1 \%)$ were at the stage of IVA followed by 105 (27.3\%) at stage III, 90 (23.4\%) were at stage IIB, and $28(7.3 \%)$ were at stage IVB. The majority of the study participants $(340,88.3 \%)$ had treatment with either curative (therapeutic) or palliative radiotherapy, 139 (36.1\%) were treated with chemotherapy, while 39 (10.1\%) had undergone surgery (Table 1).

\section{Symptom burden Main symptoms of concern}

The top five symptoms of concern a week before the interviews were pain, among 207 (53.8\%), followed by weakness $(66,17.1 \%)$, anorexia $(41,10.6 \%)$, vaginal discharge (34, 8.8\%) and constipation (31, 8.1\%), (Fig. 1); other chief presenting symptoms were urine incontinence, vaginal bleeding, headache, abdominal swelling, fever, depression, nausea, diarrhoea, leg swelling, and vomiting.

\section{Physical symptoms}

The majority $(362,94.0 \%)$ of the participants experienced at least one of the IPOS symptoms. The average overall IPOS physical symptom score was 14.9 out of 40, with a standard deviation of 9.0. This showed that the participants were moderately affected, on average, with the 10 common IPOS symptoms. Symptoms that affected at least half of the participants were pain, weakness, poor appetite, drowsiness, constipation, poor mobility, and dry mouth (Table 2 and Fig. 2). Pain was prevalent among 298 (77.4\%) of the patients, affecting them moderately to overwhelmingly in the week before the data collection, whereas, $126(32.7 \%)$ and $94(24.4 \%)$ were severely and overwhelmingly affected by pain, respectively. Weakness was also severely (112, 29.1\%) and overwhelmingly $(67,17.4 \%)$ affecting the patients. The third 


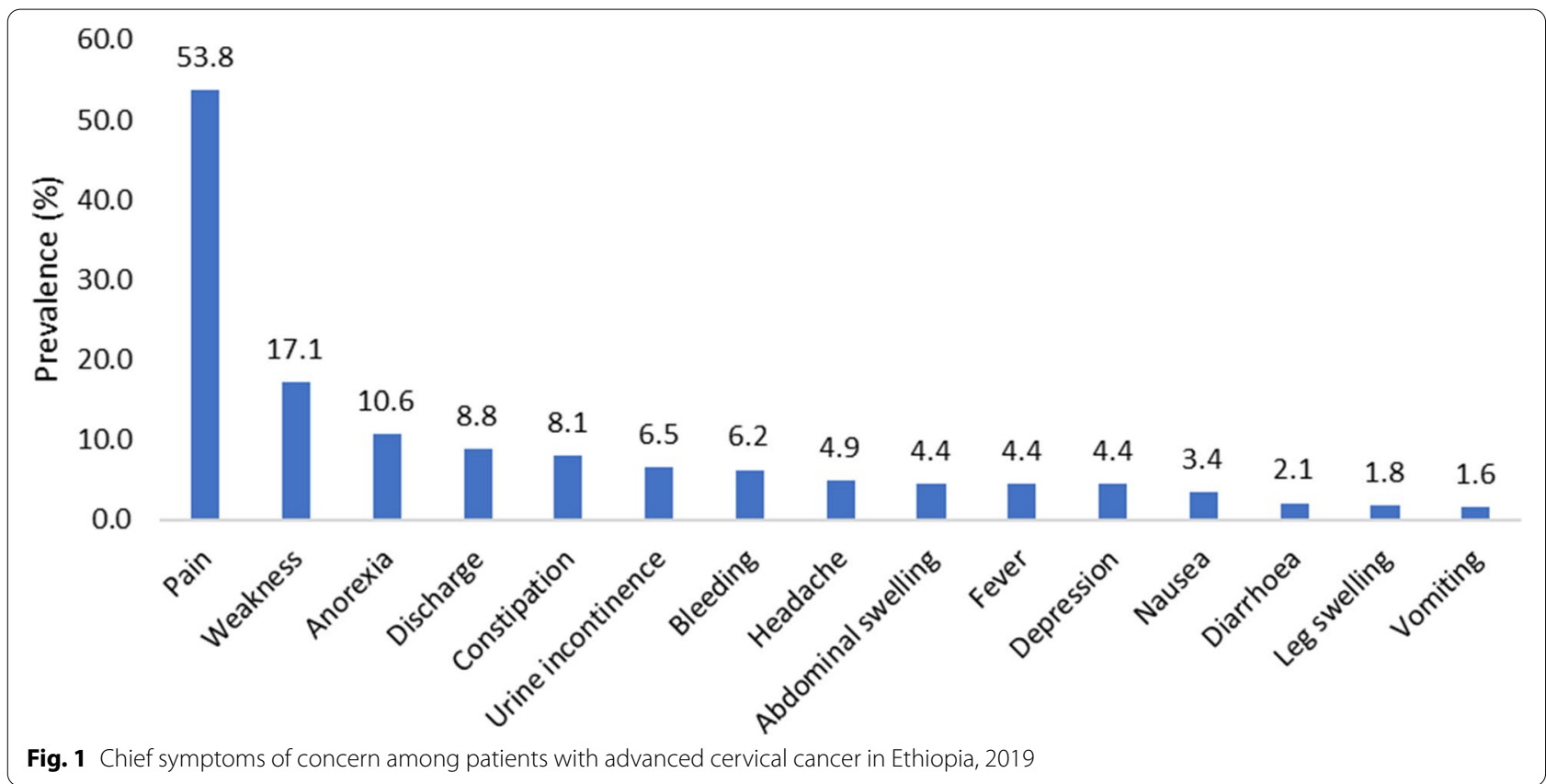

most prevalent symptom, affecting two-thirds of the patients $(232,62.3 \%)$ was poor appetite. It affected 104 (27.0\%) severely and 67 (17.8\%) overwhelmingly. Table 2 and Fig. 2 display the details of the IPOS symptoms that affected the patients a week before the interview.

\section{Emotional symptoms}

Anxiety and depression among patients and anxiety among the families were the emotional symptoms of the IPOS tool. A high proportion of the patients and their families experienced anxiety, while patient depression was relatively lower. More than three-quarters $(305,79.7 \%)$ of the study participants experienced anxiety always, mostly, or sometimes; only 37 (9.7\%) did not feel anxious at all. About one-third $(131,34.5 \%)$ of the patients did not feel depressed at all, while 176 (47.0\%) felt depressed sometimes, mostly, or always. About onethird $(117,30.8 \%)$ felt depressed most of the time or all the time. The prevalence of family anxiety was also very high; 315 (82.3\%) felt anxious sometimes, most of the time, or all the time. A significant proportion, (267, $69.7 \%$ ), did not feel at peace all the time, mostly or sometimes, while 116 (30.3\%) felt at peace always or most of the time.

\section{Social conditions and practical problems}

Social and practical problems among the study participants were prevalent. Getting required information among the patients was a concern sometimes, always, or most of the time in 185 (80.0\%) of the patients. Nearly two-thirds of the participants $(233,60.8 \%)$ felt that their practical problems such as personal and financial issues were not appropriately addressed, and a significant proportion $(161,42.0 \%)$ felt that these problems were hardly addressed. Nearly one quarter $(91,23.8 \%)$ of the participants did not usually share their feelings with their families or friends.

Other symptoms Other symptoms that affected the patients were vaginal discharge, vaginal bleeding, urine incontinence, headache, fever, abdominal swelling, diarrhoea, insomnia, and leg swelling, affecting a proportion ranging from 10.4 to $2.1 \%$, in respective order (Table 3). These symptoms have affected the patients moderately, severely, or extremely. Vaginal bleeding was a concern among $40(10.4 \%)$ mainly overwhelmingly $(32,8.3 \%)$ and severely $(6,1.6 \%)$, whereas, both vaginal discharge and urine incontinence affected 26 $(6.8 \%)$ of patients.

IPOS aggregate scores The aggregate scores of the physical, mental and social problems were calculated. The mean aggregate physical symptom score was $14.9 \pm 9.0$ out of 40 , while that of mental symptoms was $9.3 \pm 3.7$ out of 16 . The mean social problems score was $4.5 \pm 2.7$ out of 12 , while the mean overall aggregate IPOS score out of 68 was $28.6 \pm 12.1$ (Table 2). 
Table 2 IPOS symptoms among patients with advanced cervical cancer, TASH, Ethiopia, 2019

\begin{tabular}{|c|c|c|c|}
\hline Scale, Sub-scales and Items & Prevalence $^{\mathrm{a}}$ & Mean & $S D$ \\
\hline \multicolumn{4}{|l|}{ Physical symptom ${ }^{b}$} \\
\hline Pain $(n=385)$ & 77.4 & 2.5 & 1.3 \\
\hline Weakness/no energy $(n=384)$ & 68.1 & 2.1 & 1.4 \\
\hline Poor appetite $(n=377)$ & 62.3 & 2.0 & 1.5 \\
\hline Constipation $(n=383)$ & 50.4 & 1.6 & 1.5 \\
\hline Drowsiness $(n=382)$ & 48.3 & 1.5 & 1.4 \\
\hline Dry mouth $(n=380)$ & 41.3 & 1.3 & 1.3 \\
\hline Poor mobility $(n=382)$ & 39.2 & 1.3 & 1.3 \\
\hline Nausea $(n=384)$ & 29.9 & 1.0 & 1.2 \\
\hline Vomiting $(n=385)$ & 28.8 & 0.9 & 1.3 \\
\hline Shortness of breath $(n=381)$ & 25.7 & 0.8 & 1.1 \\
\hline Aggregate score (out of $40, n=358$ ) & & 14.9 & 9.0 \\
\hline \multicolumn{4}{|l|}{ Emotional symptoms ${ }^{c}$} \\
\hline Family anxiety $(n=383)$ & 82.3 & 2.9 & 1.3 \\
\hline Patient anxiety $(n=383)$ & 79.7 & 2.7 & 1.3 \\
\hline Depression $(n=380)$ & 47.0 & 1.5 & 1.4 \\
\hline Felt at peace ${ }^{d}(n=383)$ & 69.7 & 2.1 & 1.2 \\
\hline Aggregate score (out of $16, n=380$ ) & & 9.3 & 3.7 \\
\hline \multicolumn{4}{|l|}{ Social \& practical conditions ${ }^{d}$} \\
\hline Shared feelings $(n=383)$ & 23.8 & 1.0 & 1.0 \\
\hline Had adequate information $(n=383)$ & 48.3 & 1.6 & 1.2 \\
\hline $\begin{array}{l}\text { Practical problems fully addressed } \\
(n=383)\end{array}$ & 60.8 & 1.9 & 1.6 \\
\hline Aggregate score (out of $12, n=382$ ) & & 4.5 & 2.7 \\
\hline Total score (out of $68, n=352$ ) & & 28.6 & 12.1 \\
\hline
\end{tabular}

IPOS Integrated Palliative Care Outcome Scale, TASH Tikur Anbessa Specialized Hospital, SD Standard Deviation

a Prevalence (\%) is defined as symptoms reported as moderate, severe, or devastating, or problems persisting sometimes, most of the time or always. ${ }^{b}$ Response options: $0=$ None, $1=$ Slightly, $2=$ Moderately, $3=$ Severely,

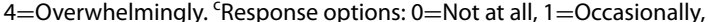

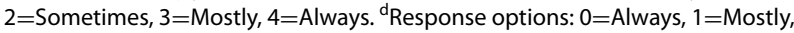
$2=$ Sometimes, $3=$ Occasionally, $4=$ Not at all

The mean physical, emotional, social and overall scores were compared among different categories of sociodemographic and disease and treatment-related variables (Table 4). Patients aged below 50 years expressed a higher score of emotional problems $(p=0.022)$ whereas illiterate patients had higher physical, social and overall problem scores $(p=0.002, p=0.020$ and $p=0.004$, respectively).

Patients who were in marriage had significantly lower emotional problems $(p=0.006)$, while patients with monthly income below USD 50.00 had shown a significantly higher burden of social problems compared to those with higher income $(p=0.000)$. Patients with FIGO stage IIB had lower physical, emotional and overall problem scores $(p<0.01)$ compared to those at stage III and stage IV. Surgery was significantly associated with emotional problems $(p=0.030)$; a significantly lower score was observed among those who underwent surgery. Patients who took treatment with therapeutic radiotherapy had significantly lower physical and emotional problems, whereas palliative radiotherapy showed a reverse effect $(p<0.01)$. The overall IPOS score was also significantly higher among those who took palliative radiotherapy $(p=0.000)$.

\section{Discussion}

This study identified the burden of symptoms among patients with advanced cervical cancer using the sevenday recall patient version III of the IPOS. Pain, weakness, and anorexia were the most concerning symptoms 7 days before the interview. Pain, poor appetite, patient anxiety, family anxiety, and poor mobility were the most prevalent symptoms. This study also identified symptoms not included in the IPOS tool, such as vaginal discharge, vaginal bleeding, and urine incontinence, which could be relevant during the development of cervical cancer-specific palliative care interventions.

Pain was the most common symptom, experienced by $77.4 \%$ of the participants and the most prevalent concern in the same period. This finding is comparable to a previous study in Ethiopia which documented that $80 \%$ of non-communicable diseases experience moderate to severe pain [26]. Other studies in Ethiopia, among patients with chronic diseases, also reported that over three-quarters of them experienced pain [27, 28]. The prevalence of pain was very high compared to a study done amongst Portuguese cancer patients [19], which reported a prevalence of $42 \%$; the pain prevalence was also higher than studies done in other countries: in Japan among cancer patients (66\%), [22], in the UK and Germany among cancer patients (62\%), [18], and in the Czech Republic among patients with chronic diseases including cancer (52\%), [29]. Another study among patients with heart failure reported a lower prevalence of $40 \%$, [24]. A higher pain prevalence could be due to poor pain control practices in Ethiopian health care settings [30,31], patient attitude [32], or socio-economic factors [33, 34]. In Ethiopia, there was documentation of the usage of weak analgesics, such as paracetamol and ibuprofen, instead of morphine and other opioids for the treatment of severe pain [35]. A study conducted among cancer patients in Ethiopia showed that about two-thirds of them received inadequate pain management; only $19 \%$ received opioids such as codeine and morphine for the management of severe pain $[28,35]$. 


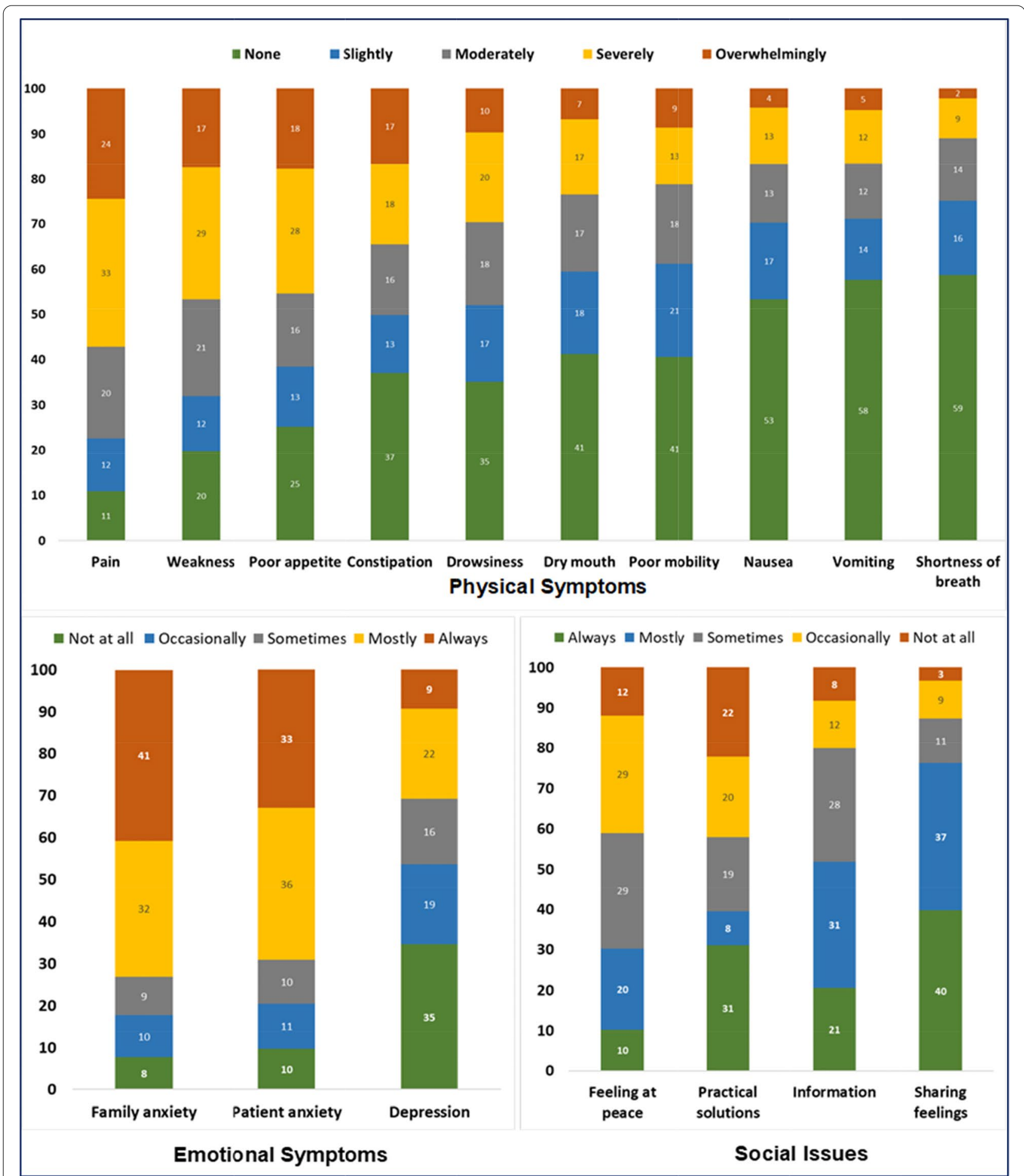

Fig. 2 Prevalence (percentage) of IPOS symptoms and problems among patients with advanced cervical cancer in Ethiopia, 2019

Weakness was the second most common symptom with a prevalence of $68.1 \%$. The symptom was less common in comparison to patients with cancer in Europe and Asia [18, 22, 29], but higher than the prevalence among Portuguese cancer patients [19] and patients with heart failure [23, 24]. Poor appetite, constipation, 
Table 3 Other physical symptoms among patients with advanced cervical cancer, TASH, Ethiopia, 2019

\begin{tabular}{|c|c|c|c|c|c|c|c|c|}
\hline \multirow[t]{3}{*}{ Symptom } & \multirow[t]{3}{*}{$P^{\mathrm{a}}$} & \multirow[t]{3}{*}{ Mean } & \multirow[t]{3}{*}{$S D$} & \multicolumn{5}{|c|}{ Frequency, Number (Percentage) } \\
\hline & & & & \multirow{2}{*}{$\begin{array}{l}\text { None } \\
0\end{array}$} & \multirow{2}{*}{$\begin{array}{l}\text { Slightly } \\
1\end{array}$} & \multirow{2}{*}{$\begin{array}{l}\text { Moder- } \\
\text { ately } \\
2\end{array}$} & \multirow{2}{*}{$\begin{array}{l}\text { Severely } \\
3\end{array}$} & \multirow{2}{*}{$\begin{array}{l}\text { Overwh- } \\
\text { elmingly } \\
4\end{array}$} \\
\hline & & & & & & & & \\
\hline Vaginal discharge & 10.4 & 0.4 & 1.2 & $345(89.6)$ & - & $2(0.5)$ & $6(1.6)$ & $32(8.3)$ \\
\hline Vaginal bleeding & 6.8 & 0.3 & 1.0 & $359(93.2)$ & - & $2(0.5)$ & $2(0.5)$ & $22(5.7)$ \\
\hline Urine incontinence & 6.8 & 0.3 & 1.0 & $359(93.2)$ & - & - & $1(0.3)$ & $25(6.5)$ \\
\hline Headache & 6.0 & 0.2 & 0.9 & $362(94.0)$ & - & $3(0.8)$ & $3(0.8)$ & $17(4.4)$ \\
\hline Fever & 5.2 & 0.2 & 0.9 & $365(94.8)$ & - & - & $1(0.3)$ & $19(4.9)$ \\
\hline Abdominal swelling & 4.9 & 0.2 & 0.8 & $366(95.1)$ & - & - & $2(0.5)$ & $17(4.4)$ \\
\hline Diarrhoea & 2.1 & 0.1 & 0.5 & 377 (97.9) & - & $2(0.5)$ & - & $6(1.6)$ \\
\hline Insomnia & 2.1 & 0.1 & 0.5 & 377 (97.9) & - & $1(0.3)$ & $1(0.3)$ & $6(1.6)$ \\
\hline Leg swelling & 2.1 & 0.1 & 0.4 & 377 (97.9) & - & $2(0.5)$ & $5(1.3)$ & $1(0.3)$ \\
\hline
\end{tabular}

TASH Tikur Anbessa Specialized Hospital, SD Standard Deviation

a $P$ refers to prevalence (\%) that is defined as symptoms reported as moderate, severe, or overwhelming

nausea, and vomiting were more prevalent compared to studies in Europe, [18, 19, 24, 29], whereas it was less common than the prevalence in Japanese cancer patients [22]. Symptoms such as drowsiness, dry mouth, lack of mobility, and shortness of break were less common [18, 19, 22, 24, 29].

Emotional symptoms, including patient anxiety, family anxiety, depression, and failure to feel at peace were common among the study participants. Anxiety among the patients was common at a prevalence of $79.7 \%$, while family anxiety was even higher at $82.3 \%$. Patient anxiety was higher than the findings among cancer patients in different countries [18, 19,24, 29], but less common than the findings in Japanese cancer patients [22]. Compared to the findings from these countries, there were comparable prevalence of family anxiety, depression, and failure to feel at peace among patients with chronic diseases.

Social interaction and solutions to practical problems such as financial and personal problems were very low. Only $23.8 \%$ of the patients shared their feelings with their families or friends. Similarly, only $48.3 \%$ felt they received as much information as they needed, while about $60 \%$ of the patients felt they had their practical problems addressed. Compared to these reports, findings in the studies referenced above show that a higher proportion of patients shared their feelings, had adequate information, and practical problems such as financial constraints solved [18, 19, 22, 24, 29].

There was a higher burden of emotional symptoms observed among women in the reproductive age group and those unmarried; this could relate to sexual activity and childbearing attitudes. Lack of support from the spouse or family could also be a contributing factor. Illiterate patients had a higher burden of physical and social problems; a lower educational status could hinder the utilisation of treatment and palliative care services as well as the education and counselling. Treatment with palliative radiotherapy and a higher stage of the disease were associated with a higher burden of physical, emotional and overall problem scores. Palliative radiotherapy, given at a late stage, added to the unmanaged side effects, could have contributed to a higher symptom burden. An explorative research could be necessary to study why palliative radiotherapy could not reduce the burden of physical and emotional symptoms.

\section{Conclusion}

This study has identified the symptoms of importance among patients with advanced cervical cancer. It also provided important symptoms in addition to the existing list in the IPOS tool. The prevalence of symptoms of concern, such as pain, weakness, and anorexia, were high in comparison to references from various countries. The burden of symptoms and problems were higher among women of childbearing age, unmarried, illiterate, those who took palliative radiotherapy, and patients with low socioeconomic status. Patients who took surgery and curative radiotherapy had a lower burden. Identification of cervical cancer-specific symptoms and 
Table 4 IPOS scores \& associated factor among patients with advanced cervical cancer, TASH, Ethiopia, 2019

\begin{tabular}{|c|c|c|c|c|}
\hline $\begin{array}{l}\text { Socio-demographic and treatment } \\
\text { information }\end{array}$ & Physical (0-40) & Emotional (0-20) & Social (0-12) & Overall (0-68) \\
\hline \multicolumn{5}{|l|}{ Age (years) } \\
\hline Below 50 & 14.86 & $9.81^{*}$ & 4.61 & 29.50 \\
\hline 50 and above & 14.92 & 8.92 & 4.41 & 27.97 \\
\hline \multicolumn{5}{|l|}{ Educational status } \\
\hline Illiterate & $16.03^{* *}$ & 9.40 & $4.73^{*}$ & $30.03^{* *}$ \\
\hline Literate & 12.98 & 9.03 & 4.07 & 26.11 \\
\hline \multicolumn{5}{|l|}{ Marital status } \\
\hline In marriage & 14.62 & $8.85^{* *}$ & 4.41 & $27.70^{*}$ \\
\hline Not in marriage & 15.34 & 9.94 & 4.62 & 29.96 \\
\hline \multicolumn{5}{|l|}{ Occupation } \\
\hline No job & 14.91 & 9.43 & 4.69 & 28.99 \\
\hline Housewife & 15.16 & 8.89 & 4.43 & 28.12 \\
\hline Farming & 16.15 & 9.46 & 5.01 & 30.29 \\
\hline Others $^{\mathrm{a}}$ & 13.84 & 9.21 & 4.18 & 27.23 \\
\hline \multicolumn{5}{|l|}{ Monthly income } \\
\hline Below 50.00 USD & 15.21 & 9.20 & $4.70^{* *}$ & 29.00 \\
\hline 50.00 USD or more & 13.20 & 9.59 & 3.36 & 26.17 \\
\hline \multicolumn{5}{|l|}{ Cancer stage } \\
\hline$\| \mathrm{B}$ & $12.30^{* *}$ & $8.07^{* *}$ & 4.49 & $24.91 * *$ \\
\hline III $(A$ or $B)$ & 15.24 & 9.02 & 4.52 & 28.68 \\
\hline IVA & 15.76 & 9.87 & 4.38 & 29.86 \\
\hline IVB & 16.86 & 10.61 & 4.93 & 32.39 \\
\hline \multicolumn{5}{|l|}{ Surgery } \\
\hline No & 14.78 & $9.40^{*}$ & 4.52 & 28.61 \\
\hline Yes & 15.94 & 8.03 & 4.23 & 28.23 \\
\hline \multicolumn{5}{|l|}{ Chemotherapy } \\
\hline No & 14.64 & 9.43 & 4.40 & 28.34 \\
\hline Yes & 15.37 & 8.96 & 4.66 & 28.98 \\
\hline \multicolumn{5}{|l|}{ Therapeutic radiotherapy } \\
\hline No & $16.39^{* *}$ & $9.86^{* *}$ & 4.43 & 30.65 \\
\hline Yes & 12.28 & 8.19 & 4.58 & 24.87 \\
\hline \multicolumn{5}{|l|}{ Palliative radiotherapy } \\
\hline No & $12.53^{* *}$ & $8.26^{* *}$ & 4.51 & $25.24^{* *}$ \\
\hline Yes & 16.77 & 10.06 & 4.47 & 31.22 \\
\hline Aggregate & 14.90 & 9.26 & 4.49 & 28.57 \\
\hline
\end{tabular}

IPOS Integrated Palliative Care Outcome Scale, TASH Tikur Anbessa Specialized Hospital, USD United States Dollar

${ }^{a}$ Others include retired, employees, petty traders and daily labourers; * Significantly different at 0.05 using t-test or one-way analysis of variance; ** Significantly different at 0.01 using t-test or one-way analysis of variance

concerns could help to design and implement targeted palliative care interventions. We recommend early detection and alleviation of these symptoms and concerns to improve the quality of life of the patients.

\section{Abbreviations}

FIGO: International Federation of Gynaecology and Obstetrics; GLOBOCAN: Global Observatory of Cancer; IPOS: Integrated Palliative Care Outcome Scale;
STROBE: Strengthening the Reporting of Observational Studies in Epidemiology; UNISA: University of South Africa; WHO: World Health Organization.

\section{Acknowledgements}

We acknowledge the Radiotherapy Center of the Tikur Anbessa Specialised Hospital in Addis Ababa for permitting data access and facilitating the data collection process. We also acknowledge the University of South Africa for providing financial support for the research. We offer special thanks to Dr. Wondemagegnehu Tigeneh and Sr. Askale Yakob for their support through the protocol approval and data collection period. We also thank all the respondents for their willingness to provide the necessary information. 


\section{Authors' contributions}

TK conducted research design, data collection, cleaning, and analysis. TK, AHM, and AM conducted the write-up of this research article. All have reviewed and approved the final version of this manuscript.

\section{Funding}

The corresponding author and the UNISA funded this research. The UNISA provided a student bursary that covered data collectors' payments and the cost of duplication of the questionnaire. Other research expenses are covered by the principal researcher.

\section{Availability of data and materials}

This study is part principal author's PhD thesis at UNISA. The dataset collected and analysed in this study is available from the corresponding author upon reasonable request and after UNISA grants permission.

\section{Declarations}

\section{Ethics approval and consent to participate}

The Institutional Review Board of the College of Health Sciences, Addis Ababa University granted ethical approval for this research (PN-058/18/IM), and all methods performed were in accordance with the relevant guideline and regulations. The Research Ethics Committee, Department of Health Studies of the UNISA also approved this research. In addition, the Radiotherapy Center of the Tikur Anbessa Specialised Hospital in Addis Ababa provided written permission. All the respondents received information regarding the research, and they provided informed consent before the interview.

\section{Consent for publication}

Not applicable. Individuals' information, images, or videos are not included in this report.

\section{Competing interests}

The authors declare that they have no competing interests.

\section{Author details}

'Student at University of South Africa, Ethiopia Learning Centre, Addis Ababa, Ethiopia. ${ }^{2}$ Department of Health Studies, University of South Africa, Pretoria, South Africa.

Received: 28 September 2021 Accepted: 15 November 2021 Published online: 18 December 2021

\section{References}

1. Omran AR. The epidemiologic transition: a theory of the epidemiology of population change. 1971. Milbank Q. 2005;83(4):731-57.

2. Fitzmaurice $\mathrm{C}$, Abate D, Abbasi N, Abbastabar H, Abd-Allah F, AbdelRahman O, et al. Global, regional, and National Cancer Incidence, mortality, years of life lost, years lived with disability, and disability-adjusted life-years for 29 Cancer groups, 1990 to 2017: a systematic analysis for the global burden of disease study. JAMA Oncology. 2019;5(12):1749-68.

3. Ferlay J, Soerjomataram I, Dikshit R, Eser S, Mathers C, Rebelo M, et al. GLOBOCAN 2012: estimated Cancer incidence, mortality and prevalence worldwide in 2012. Int J Cancer. 2015;136(5):E359-86.

4. Araya LT, Fenta TG, Sander B, Gebremariam GT, Gebretekle GB. Healthrelated quality of life and associated factors among cervical Cancer patients at Tikur Anbessa specialized hospital, Addis Ababa, Ethiopia. Health Qual Life Outcomes. 2020;18(72):1-9.

5. Ayenew AA, Zewdu BF, Nigussie AA. Uptake of cervical Cancer screening service and associated factors among age-eligible women in Ethiopia: systematic review and Meta-analysis. Infect Agent Cancer. 2020;15(67):1-17.

6. Jembere GB, Cho Y, Jung M. Decomposition of Ethiopian life expectancy by age and cause of mortality; 1990-2015. Plos One. 2018;13(10):1-15.

7. Tsegay A, Araya T. Knowledge, attitude, and practice on cervical Cancer screening and associated factors among women aged 15-49 years in Adigrat town, northern Ethiopia, 2019: a community-based cross-sectional study. Int J Womens Health. 2020;2020(12):1283-98.
8. Woldu BF, Lemu LG. Comprehensive knowledge towards cervical Cancer and associated factors among women in Durame town, Southern Ethiopia. J Cancer Epidemiol. 2020;2020(1):1-6.

9. WHO. Comprehensive Cervical Cancer Control: a Guide to Essential Practice. 2nd ed. Geneva: World Health Organization; 2014. p. 191-213.

10. Erku DA. Complementary and alternative medicine use and its association with quality of life among Cancer patients receiving chemotherapy in Ethiopia: a cross-sectional study. Evid Based Complement Alternat Med. 2016;2016(1):1-8

11. Dudgeon D. The impact of measuring patient-reported outcome measures on quality of and access to palliative care. J Palliat Med. 2018;21(S1):S76-80.

12. Jang ES, Kim YS, Kim KA, Lee YJ, Chung WJ, Kim IH, et al. Factors associated with health-related quality of life in Korean patients with chronic hepatitis C infection using the SF-36 and EQ-5D. Gut Liver. 2018;12(4):440-8.

13. Eagar K, Senior K, Fildes D, Quinsey K, Owen A, Yeatman H, et al. The palliative care evaluation tool kit: a compendium of tools to aid in the evaluation of palliative care projects. In: University of Wollongong Research Online. Australia: University of Wollongong; 2004. p. 1-12.

14. Hearn J, Higginson I. Development and validation of a Core outcome measure for palliative care: the palliative care outcome scale. Palliative care Core audit project advisory group. Qual Health Care. 1999;8(4):219-27.

15. Von Elm E, Altman DG, Egger M, Pocock SJ, Gøtzsche PC, Vandenbroucke $J$, et al. The strengthening the reporting of observational studies in epidemiology (Strobe) statement: guidelines for reporting observational studies. Int J Surg. 2014;12(12):1495-9.

16. Bendedet J, Bender $\mathrm{H}$, Jones $\mathrm{H}$. Staging classifications and clinical practice guidelines in the Management of Gynecologic Cancers. Int J Gynaecol Obstet. 2000;70(2):207-312.

17. Hata M, Koike I, Miyagi E, Asai-Sato M, Kaizu H, Mukai Y, et al. Radiation therapy for patients with bone metastasis from uterine cervical Cancer: its role and optimal radiation regimen for palliative care. Anticancer Res. 2018;38(2):1033-40.

18. Murtagh FE, Ramsenthaler C, Firth A, Groeneveld El, Lovell N, Simon ST, et al. A brief, patient- and proxy-reported outcome measure in advanced illness: validity, reliability and responsiveness of the integrated palliative care outcome scale (IPOS). Palliat Med. 2019;33(8):1045-57.

19. Antunes B, Ferreira PL. Validation and cultural adaptation of the integrated palliative care outcome scale (IPOS) for the Portuguese population. BMC Palliat Care. 2020;19(178):1-11.

20. Laissaar M, Hallik R, Sillaste P, Ragun U, Parn ML, Suija K. Translation and cultural adaptation of IPOS (integrated palliative care outcome scale) in Estonia. J Patient RepOutcomes. 2021;5(15):1-12.

21. Raj R, Ahuja K, Frandsen M, Murtagh FEM, Jose M. Validation of the IPOS-renal symptom survey in advanced kidney disease: a cross-sectional study. J Pain Symptom Manag. 2018;56(2):281-7.

22. Sakurai H, Miyashita M, Imai K, Miyamoto S, Otani H, Oishi A, et al. Validation of the integrated palliative care outcome scale (IPOS) - Japanese version. Jpn J Clin Oncol. 2019;49(3):257-62.

23. Oriani A, Guo P, Gadoud A, Dunleavy L, Kane P, Murtagh FEM. What are the Main symptoms and concerns reported by patients with advanced chronic heart failure?-a secondary analysis of the palliative care outcome scale (POS) and integrated palliative care outcome scale (IPOS). Ann Palliat Med. 2019:8(5):775-80.

24. Roch C, Palzer J, Zetzl T, Stork S, Frantz S, van Oorschot B. Utility of the integrated palliative care outcome scale (IPOS): a cross-sectional study in hospitalised patients with heart failure. Eur J Cardiovasc Nurs. 2020;19(8):702-10.

25. Ellis-Smith C, Higginson IJ, Daveson BA, Henson LA, Evans CJ. How can a measure improve assessment and Management of Symptoms and Concerns for people with dementia in care homes? A mixed-methods feasibility and process evaluation of IPOS-Dem. Plos One. 2018;13(7):1-29.

26. Reid EA, Gudina EK, Ayers N, Tigineh W, Azmera YM. Caring for life-limiting illness in Ethiopia: a mixed-methods assessment of outpatient palliative care needs. J Palliat Med. 2018:21(5):622-30.

27. Tuem KB, Gebremeskel L, Hiluf K, Arko K, Hailu HG. Adequacy of Cancerrelated pain treatments and factors affecting proper Management in Ayder Comprehensive Specialized Hospital, Mekelle, Ethiopia. J Oncol. 2020;2020(1):1-10. 
28. Tegegn HG, Gebreyohannes EA. Cancer Pain Management and Pain Interference with Daily Functioning among Cancer Patients in Gondar University Hospital. Pain Res Manag. 2017;2017:5698640.

29. VIckova K, Hoschlova E, Chroustova E, Loucka M. Psychometric properties of the Czech integrated palliative outcome scale: reliability and content validity analysis. BMC Palliat Care. 2020;19(39):1-8.

30. Temesgen MM, Alemu T, Shiferaw B, Legesse S, Zeru T. Prevalence of oncogenic human papillomavirus (HPV 16/18) infection, cervical lesions and its associated factors among women aged 21-49 years in Amhara region, Northern Ethiopia. Plos One. 2021;16(3):1-12.

31. Nugusse T, Lemlem SB, Deressa J, Kisa S. Prevalence of fatigue and associated factors among Cancer patients attending Tikur Anbessa specialized hospital, Addis Ababa, Ethiopia. Cancer Manag Res. 2021;13(1):1909-16.

32. Lou F, Shang S. Attitudes towards Pain Management in Hospitalized Cancer Patients and their Influencing Factors. Chin J Cancer Res. 2017:29(1):75-85.

33. Leysen L, Beckwée D, Nijs J, Pas R, Bilterys T, Vermeir S, et al. Risk factors of pain in breast Cancer survivors: a systematic review and Meta-analysis. Support Care Cancer. 2017;25(12):3607-43.

34. Smyth JA, Dempster M, Warwick I, Wilkinson P, McCorry NK. A systematic review of the patient- and Carer-related factors affecting the experience of pain for advanced Cancer patients cared for at home. J Pain Symptom Manag. 2018;55(2):496-507.

35. Zeru T, Gerensea H, Berihu H, Zeru M, Wubayehu T. Nurses practice towards palliative care in Shire Endasilasie health facilities, northern Ethiopia: a cross-sectional study. Pan Afr Med J. 2020;35(110):1-7.

\section{Publisher's Note}

Springer Nature remains neutral with regard to jurisdictional claims in published maps and institutional affiliations.

- fast, convenient online submission

- thorough peer review by experienced researchers in your field

- rapid publication on acceptance

- support for research data, including large and complex data types

- gold Open Access which fosters wider collaboration and increased citations

- maximum visibility for your research: over $100 \mathrm{M}$ website views per year

At BMC, research is always in progress.

Learn more biomedcentral.com/submissions 